\title{
Clouded in mystery: the global trade in clouded leopards
}

\author{
Neil D'Cruze ${ }^{1,2} \cdot$ David W. Macdonald ${ }^{1}$
}

Received: 8 May 2015/Revised: 29 August 2015/Accepted: 22 September 2015/

Published online: 13 October 2015

(C) The Author(s) 2015. This article is published with open access at Springerlink.com

\begin{abstract}
In the first global review focused specifically on clouded leopard trade, we assess its impact on the basis of information gathered from annual CITES reports, literature and expert opinion. Although international and domestic trade regulations are in place, in 'exceptional circumstances' trade in Asian big cats is legally permitted. More generally, and irrespective of its legal status, trade also has potential to compromise wild animal welfare. We report an apparent shift toward commercial trade in captive bred clouded leopards, trade irregularities that point toward possible laundering of wild caught animals, and document the presence of individuals on 'tiger farms' in south-east Asia and a 'lion park' in South Africa. We found CITES records contradictory and incomplete, with data on source country particularly lacking. This study highlights 'legal loopholes' that apply to all Asian big cat species. As a precautionary measure, we support calls to extend existing bans on Asian big cat trade so that they include commercial trade in captive bred individuals. Illegal trade in derivatives can openly be observed online and at wildlife markets in range countries where enforcement is weak. However, an energetic search has revealed that specific information regarding clouded leopards is lacking. We argue that this is not grounds for complacency, but rather suggests a need for research into trade dynamics, cooperation between national enforcement agencies, improved compliance with trade data management systems, the destruction of private held stockpiles and the revision of existing legal frameworks to prevent illegal trade in these and other threatened wild felids.
\end{abstract}

Communicated by Dirk Sven Schmeller.

Electronic supplementary material The online version of this article (doi:10.1007/s10531-015-1010-9) contains supplementary material, which is available to authorized users.

Neil D'Cruze

neil.dcruze@zoo.ox.ac.uk

1 The Wildlife Conservation Research Unit, Department of Zoology, University of Oxford, The Recanati-Kaplan Centre, Tubney House, Abingdon Road, Tubney OX13 5QL, UK

2 World Animal Protection, 5th Floor, 222 Grays Inn Road, London WC1X 8HB, UK 
Keywords Animal welfare - Asia - Captive breeding - CITES - Conservation · Enforcement . Illegal wildlife trade $\cdot$ Neofelis diardi $\cdot$ Neofelis nebulosa

\section{Introduction}

Demand for felids is not new; the allure of their fur and teeth as decorative items can probably be traced back to the first humans brave enough to slay a large fearsome predator (Nowell and Jackson 1996) and the social cachet of adornment with felid derivatives is still apparent in many cultures (Fitzherbert et al. 2014). Similarly, the collection of wild felids for entertainment and companionship has been part of human culture since prehistory (Driscoll et al. 2009). At least 2000 years old, ancient Asian texts document the perceived medicinal and spiritual properties of their derivatives (Nowell and Jackson 1996) and felid body parts feature prominently in illegal wildlife trade to this day (Dutton et al. 2013).

Formerly considered a single species (Neofelis nebulosa), clouded leopards have recently been split into two distinctive species. The Sunda clouded leopard (Neofelis diardi) of Sumatra and Borneo was recently given specific status based on analysis of mitochondrial DNA, microsatellites and morphology (Buckley-Beason et al. 2006; Kitchener et al. 2006). It is thought that the Sunda clouded leopard diverged from its mainland counterpart [which is now referred to as the clouded leopard (Neofelis nebulosa)] approximately 1.5 million years ago due to geographic isolation (Kitchener et al. 2006).

Clouded leopards (Genus Neofelis) are named after the distinctive dark markings on their attractive coat, reminiscent of 'clouds' (Nowell and Jackson 1996). The tail of these medium-sized cats is thick, plush and relatively elongated in comparison to other Asian cats (Nowak 2005). The upper canines are also relatively longer than those of any other living species of felid (Nowak 2005). In captivity, individuals belonging to these species have been described as 'gentle and playful' with an affinity for 'being petted by their custodians' (Nowak 2005). Taken together, these characteristics make it unsurprising that global demand for clouded leopards and their derivatives persists.

In recent decades, hundreds of clouded leopard skins have been noted during market surveys throughout Asia (e.g. Salter 1983; Nowell 1990; Low 1991; Nijman and Shepherd 2015). Similarly, researchers have also documented trade in their bones for medicines, meat for exotic dishes and live animals for use in the exotic pet trade (Nowell and Jackson 1996; Sanderson et al. 2008; Nijman and Shepherd 2015; Harrington 2015). A recent survey of illegal big cat derivatives at selected markets in Myanmar revealed clouded leopards to be the most frequently traded species of big cat (482 individuals) (Nijman and Shepherd 2015). As a source of comparison, researchers found clouded leopard trade to be more than double that observed for tigers at these locations (Panthera tigris) (207 individuals) (Nijman and Shepherd 2015). As such, this trade raises concern for both clouded leopard conservation and welfare.

With regards to conservation status, both $N$. nebulosa and $N$. diardi have been listed as 'Vulnerable' on the International Union for the Conservation of Nature (IUCN) Red List of Threatened species since 1986 and 2008 respectively (Sanderson et al. 2008; Hearn et al. 2008). The total effective population size is suspected to be fewer than 10,000 mature individuals for each species, with no single population numbering more than 1000 individuals (Sanderson et al. 2008; Hearn et al. 2008). In comparison to other big cat species, there are thought to be less than 3200 tigers (Goodrich et al. 2015) and less than 20,000 
lions (Panthera leo) (Bauer et al. 2015) remaining in the wild. According to zoological records, 267 individual clouded leopards are formally registered at 61 different institutions throughout Asia, Europe and the USA (International Species Information System (ISIS) 2014).

Deforestation is thought to be the foremost threat as clouded leopards are strongly associated with primary tropical forest in the parts of the world where it is being felled most rapidly, including Southeast Asia (Grassman et al. 2005; Austin and Tewes 1999) (Bangladesh; Bhutan; Cambodia; China; India; Indonesia; Lao People's Democratic Republic [Lao PDR]; Malaysia; Myanmar; Nepal; Thailand; Vietnam Sanderson et al. 2008; Hearn et al. 2008). The threat to Sunda clouded leopards from habitat loss is modeled in detail by Macdonald et al. (In prep). However, illegal trade is among the fastest and most destructive threats to many wild felid populations (e.g. tigers) when it stems from poaching for commercial purposes (Nowell and Jackson 1996; Macdonald et al. 2012).

Consequently, trade in clouded leopards has been regulated internationally since 1975 when the convention on International Trade in Endangered Species of Wild Fauna and Flora (CITES) first came into force. Clouded leopards are included on Appendix I of CITES, which stipulates that trade in specimens of this species is permitted only in exceptional circumstances. This includes the commercial trade in captive bred individuals and specimens that were acquired before CITES provisions applied to them (commonly referred to as pre-convention specimens) (UNEP-WCMC 2014). All clouded leopard range countries are currently Party to CITES (UNEP-WCMC 2014). On a domestic scale, hunting bans are also in place across all of the known clouded leopard range countries (e.g. the Wildlife Protection Act 1972 in India; the Wildlife Reservation and Protection Act in Thailand; and the Wildlife and Wild Plants and Conservation of Natural Areas Law in Myanmar) (Sanderson et al. 2008).

Regarding animal welfare, all clouded leopard trade, irrespective of its legality or whether it involves live animals or their derivatives, clearly has capacity to compromise good wild animal welfare (Baker et al. 2013). The potential for suffering exists at all stages of the trade process including capture, slaughter, transport and any resulting captivity (Baker et al. 2013). The intensity and duration of suffering will depend on whether and

Fig. 1 Logical distribution of clouded leopard trade scenarios. Wildlife trade is either legal or illegal (e.g. international legislation such as CITES and domestic legislations such as national hunting bans); that either goes recorded or unrecorded

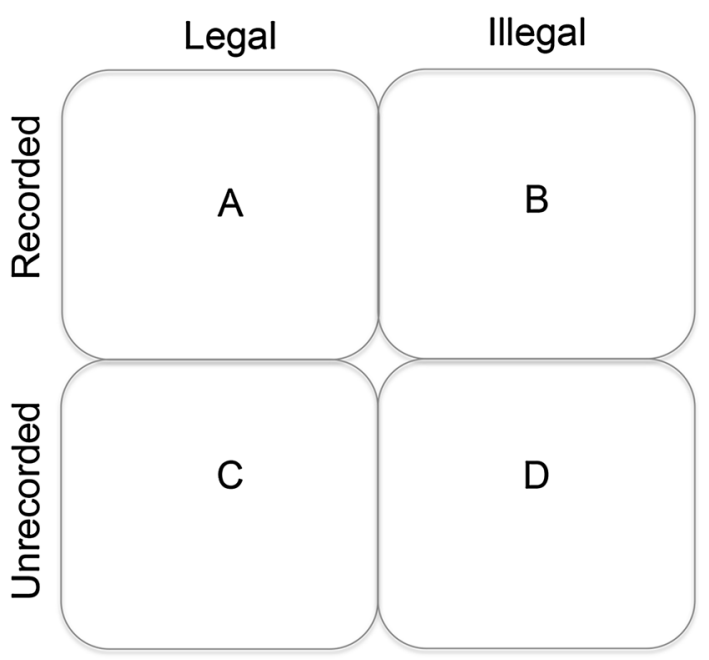


how the animal is restrained, transported, kept, fed and watered, marketed, and either killed or used alive (Baker et al. 2013).

Herein, we review annual CITES reports, scientific literature, grey literature and expert opinion to examine the current trade in clouded leopards. We asked: (1) which types of trade are most prevalent; (2) what are the major trade routes (both domestic and international); and (3) how much impact is trade currently thought to be having on this species? We hope that the information gathered will help to guide existing efforts to both conserve remaining wild populations and ensure the welfare of individual clouded leopards.

\section{Methods}

We gathered data from four main sources: (1) Trade records from the annual reports of CITES member states; (2) scientific literature; (3) grey literature; and (4) expert opinion. From these, we sought to assess trends on a global scale and to sample both legal and illegal trade that was either officially recorded or unrecorded (Fig. 1).

\section{CITES records review}

States party to CITES are required to submit annual reports of international trade in listed species, which are made available on the United Nations Environment Program World Conservation Monitoring Centre (UNEP-WCMC) CITES trade database (www.unepwcmc-apps.org/citestrade/trade.cfm). These data have proved revealing in previous studies of legal trade in wild mammals (e.g. Bush et al. 2014; Harrington 2015). We queried the database for all records of trade in $N$. nebulosa, $N$. diardi, and Neofelis spp. for the years 1975-2013 inclusive (2013 being the most recent complete year) to best approximate the clouded leopard trade recorded through CITES.

Trade data on clouded leopards were supplied in the form of a Comparative Tabulation Table (data collated 01 May 2014-see UNEP-WCMC (2014) for detailed explanation on data) (Appendix of ESM 1). This output was deliberately chosen as (in addition to export and import data) it also provides information (where available) on the source and purpose of wildlife trade transactions (UNEP-WCMC 2014).

All purpose codes used by CITES Parties (as outlined in Notification 2002/022) were used in the analysis including: captive breeding, circus, commercial, educational, personal, scientific, and zoo use (UNEP-WCMC 2014). Similarly, all source codes were also used in the analysis including: captive born, commercial captive bred, non-commercial captive bred, pre-convention, seized, source unknown, ranched and wild caught (UNEP-WCMC 2014). We analyzed seized clouded leopards (both live animals and derivatives) separately.

All reported trade terms used by CITES Parties (as outlined in Notification 2002/022) were included in the analysis (UNEP-WCMC 2014). We allocated these reported trade terms to one of three main categories: live (comprising only live individuals), derivatives (comprising body parts, bones, skins, specimens and unknown). Trade records that lacked a specific source, purpose, trade term and/or unit code were identified as 'blank' and were included in analyses. All reported unit codes used by CITES (as outlined in Notification 2002/022) were also included in the analysis (UNEP-WCMC 2014).

The analysis covers three main reporting periods: 1975 and 1981; 1982 and 1997; and 1998 and 2013. The main focus covers the latter two 15 year periods, which allows for comparisons of trade and reporting over time. In the first few years following the 
Convention's entry into force (1975 and 1981), there were substantially fewer Parties (62), a lower number of reported transactions and poorer quality data due to incomplete reporting at that time (UNEP-WCMC 2014).

We used these data to identify the countries that are most actively involved in the regulated trade of clouded leopards and their derivatives. Data were included where a CITES country could not be allocated, for instance where the origin or exporter was reported as 'unknown' or 'various'. Following the completion of this review we described tabulated categorical data using descriptive statistics (e.g. percentages, pie charts and bar charts). We also subjected tabulated data to simple regression analysis using SPSS statistical software (version 22.0, IBM SPSS Statistics, New York, USA) to provide insight into clouded leopard trade trends over the selected study period. For all analyses we used the declared state of origin over exporting country if data were available and were different.

\section{Literature survey}

Predetermined criteria were used to search the on-line library database 'Web of Knowledge' for scientific papers written in English, published between 1975 and 2013, containing the terms 'clouded leopard', 'Neofelis nebulosa' and 'Neofelis diardi'. We searched all available fields including title, abstract, article, topic, and full text. All items were screened for eligibility against the following review criteria: full text can be accessed and reference is made to trade of clouded leopards (Fig. 2).

We also searched the websites of international NGOs (Appendix of ESM 2) relevant to the trade of wild species (Fig. 2). Where a publication list was available, we downloaded all reports published from 1975 to 2013 that fulfilled the query 'clouded leopard' found through the search facility if present. Alternatively, we took the first 10 downloadable reports from the publications page if a search could not be made. We also included

(1) Scientific Literature

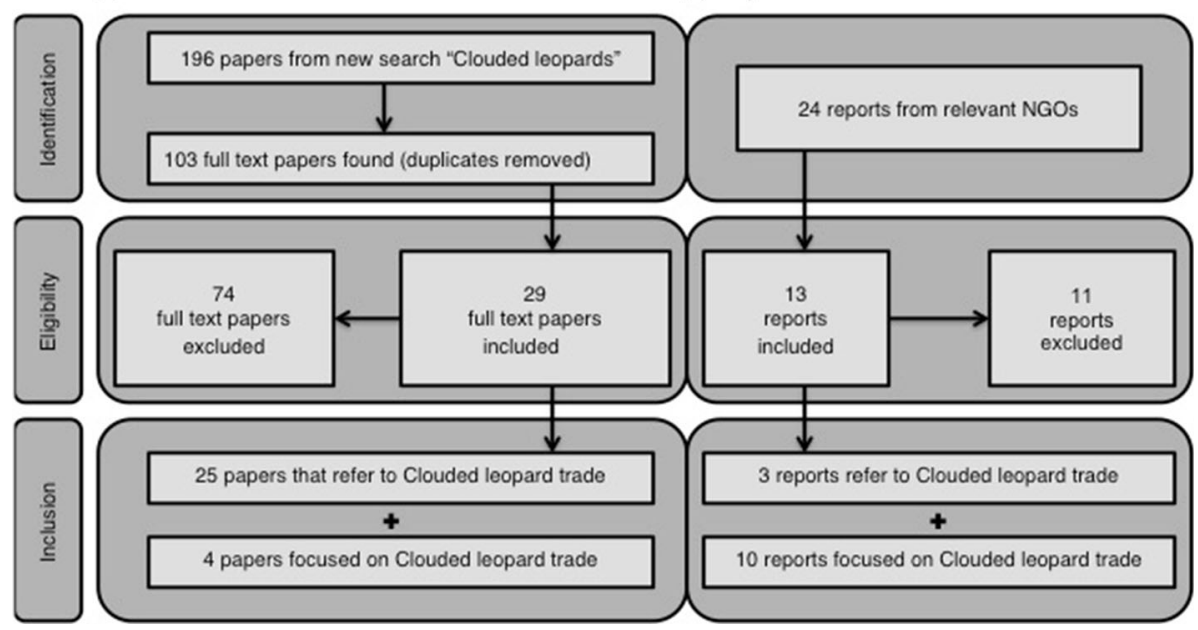

Fig. 2 The search strategy detailing identification, screening, eligibility, and inclusion of research articles from the scientific literature and the grey literature (publications from NGO's working on this issue) in a systematic review of the trade in clouded leopards 
additional reports as recommended by relevant experts via our expert questionnaire. A report was eligible if it made reference to trade in clouded leopards.

We gave each selected article (paper or report) a unique identification code and noted full citation details, including year of publication (Appendix of ESM 2). Where available, we recorded additional information regarding the type, purpose, source and destination of clouded leopards or their derivatives. We also made a note of any references to the impact of clouded leopard trade on either the conservation or the welfare of this species. Following the completion of this review we subjected tabulated data to simple regression analysis using SPSS statistical software to provide insight into publication trends over the selected study period.

\section{Expert survey}

We conducted a questionnaire survey of people involved in clouded leopard research, conservation, or management throughout the world between October 2014 and January 2015. We distributed the self-administrated questionnaire to the members of the International Union for the Conservation of Nature Species Survival Commission Cat Specialist Group (IUCN, SSC CSG) and other recommended relevant experts (including academic researchers, field biologists and legal experts all of whom had been active for more than 5 years on this issue) by email. The self-administrated questionnaire and all communication were in English and no translation was involved in the survey.

The questionnaire consisted of 14 questions eliciting knowledge and opinions of respondents pertaining to: (1) the trends in, and scale of, clouded leopard trade; (2) the current major trade routes of the trade; and (3) the impacts of trade on the conservation and welfare of this species (Appendix of ESM 3). Completed questionnaires were checked and, when necessary, further correspondence was carried out with respondents to clarify the information provided.

\section{Results}

\section{CITES search strategy and data extraction}

During the period 1975 and 2013 a total of 316 separate clouded leopard trade records (including seizures) was officially received by CITES according to the comparative tabulation report (Appendix of ESM 1). It is important to note that to date the CITES records have not differentiated between specimens of Neofelis diardi and Neofelis nebulosa and the search term 'Neofelis spp.' did not retrieve any records. The majority (71 \%;n=223) of these CITES trade records referred to live clouded leopards (Appendix of ESM 1). The remainder referred to clouded leopard derivatives including skins (11\%), specimens $(10 \%)$, body parts $(5 \%)$, bones $(2 \%)$ and unspecified 'derivatives' (1\%) (with no additional descriptive data being provided) (Appendix of ESM 1).

Each CITES trade transaction record should be composed of data relating to both export and import aspects of a transaction, including the type and quantity of items traded. However, CITES WCMC acknowledges that trade between two countries, involving the same shipments, frequently fails to show perfect correlation (UNEP-WCMC 2014). We found that $43 \%(n=137)$ of the 316 clouded leopard CITES records provided export data only, $48 \%$ provided import data only and only $9 \%$ provided both export and import data 


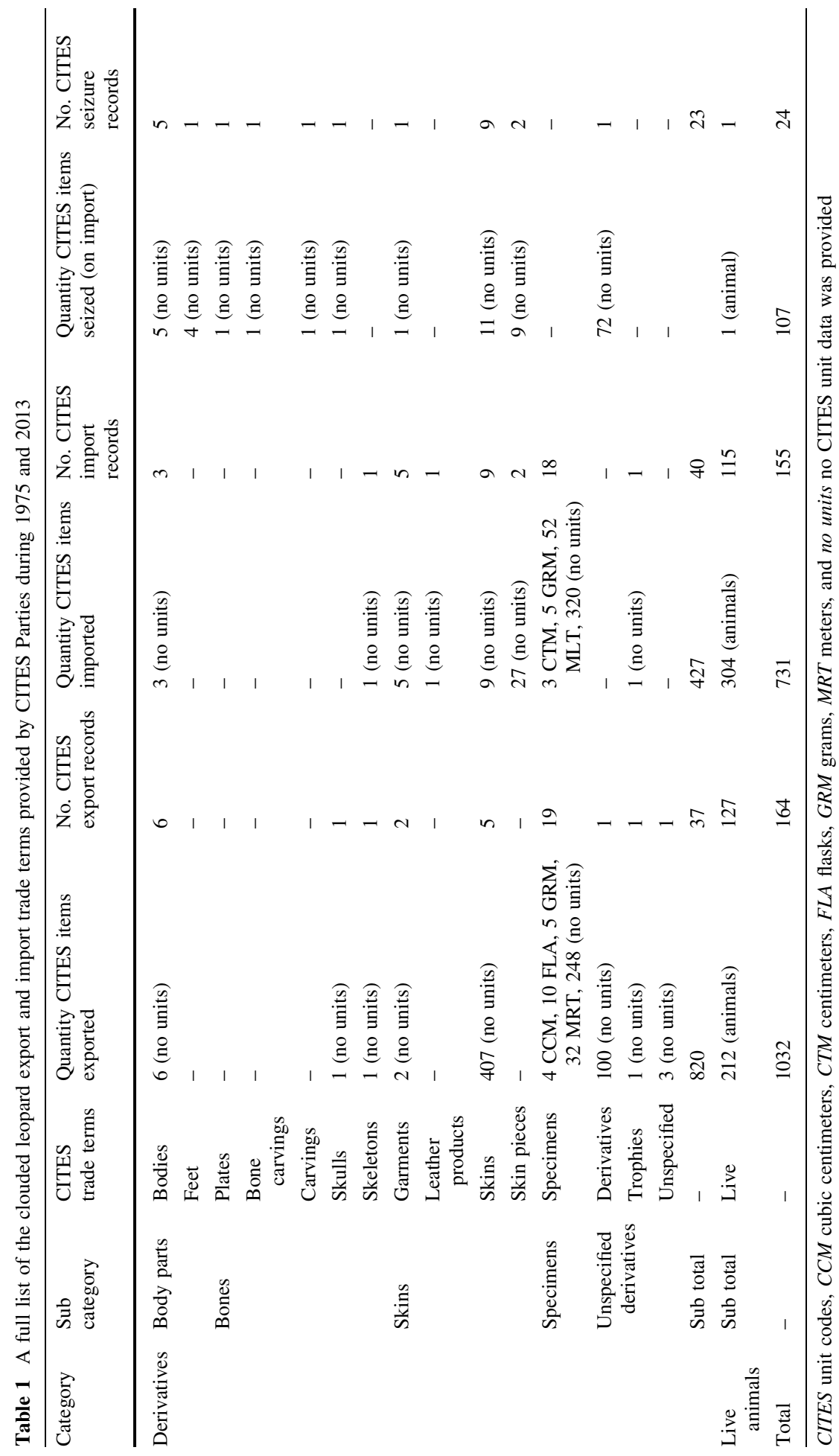


(Appendix of ESM 1). The number of CITES trade transaction records lacking export data and import data is not a recent phenomenon and has remained constant feature since records began in 1975 (UNEP-WCMC 2014).

\section{Derivative trade recorded by CITES}

In total, $22 \%(n=70)$ of the 316 CITES records referred to the legal trade in clouded leopard derivatives (Appendix of ESM 1). CITES records indicate that in terms of quantity, a total of 820 derivatives was legally exported via 37 trade transactions and 427 derivatives was legally imported via 40 trade transactions between 1975 and 2013 (Table 1). However, we found that the information regarding the units used to describe these legal derivative imports and exports were provided for only $7 \%(n=5)$ of export records (four cubic centimeters, 10 flasks, five grams and $32 \mathrm{~mm}$ in total) and $6 \%(n=4)$ of import records (three centimeters, five grams and $52 \mathrm{~mm}$ in total) respectively (Table 1). As this information is required fully to comprehend and compare the quantity of derivatives involved

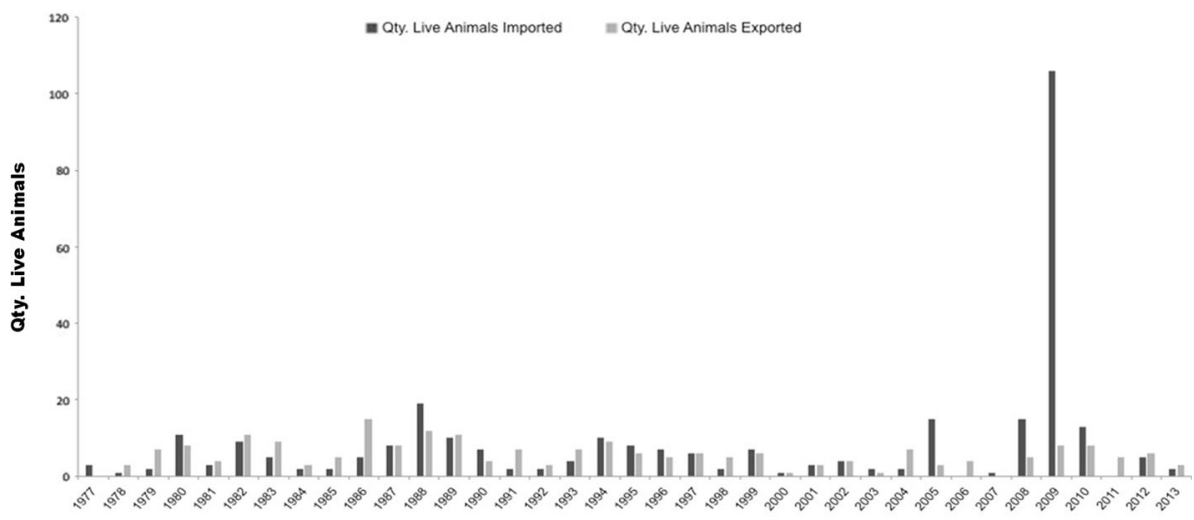

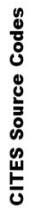

$1975-1981$
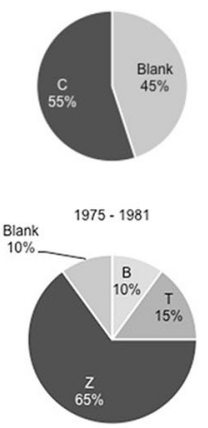
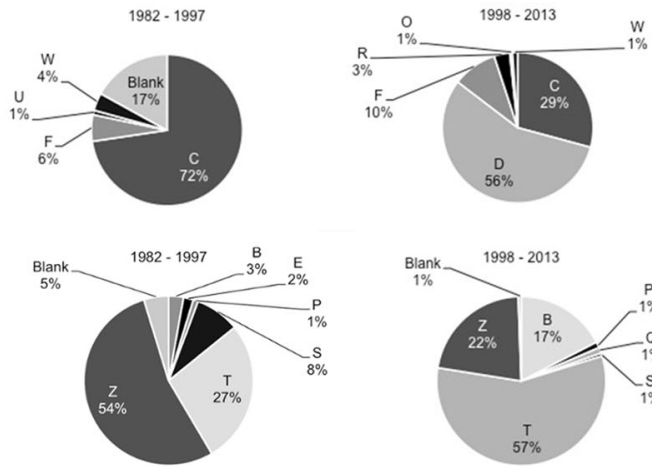

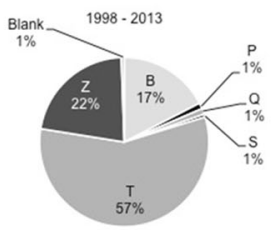

Fig. 3 Exports and Imports of live clouded leopards between 1975 and 2013 (bar chart) with relative proportions of import sources and purposes over the periods 1975 and 1981; 1982 and 1997; and 1998 and 2013 (pie charts). CITES source codes, Blank unspecified, $C$ animals bred in captivity, $D$ bred in captivity for commercial purposes, $F$ animals born in captivity ( $\mathrm{F} 1$ or subsequent generations), $R$ ranched specimens; and $W$ specimens taken from the wild. CITES purpose codes: Blank unspecified, $B$ breeding in captivity, $E$ educational, $P$ personal, $Q$ circus or travelling exhibition, $S$ scientific, $T$ commercial use, and $Z$ zoo 
70

\section{Export Qty. Live Animals}

BL

60

50

40

$\mathrm{BL}$

30

20

$B L$

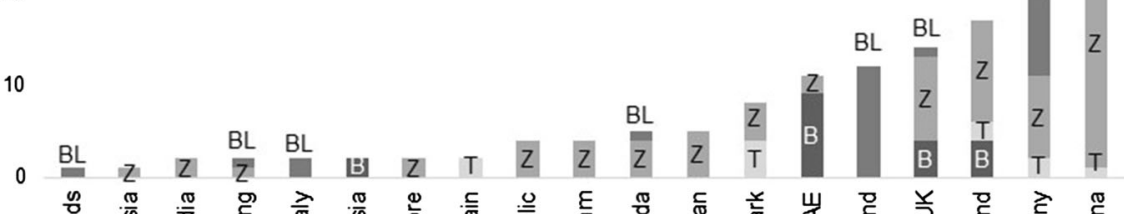

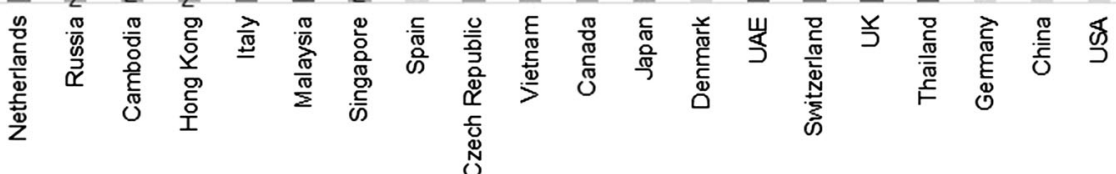

140

Import Qty. Live Animals

120

100

80

60

40

20

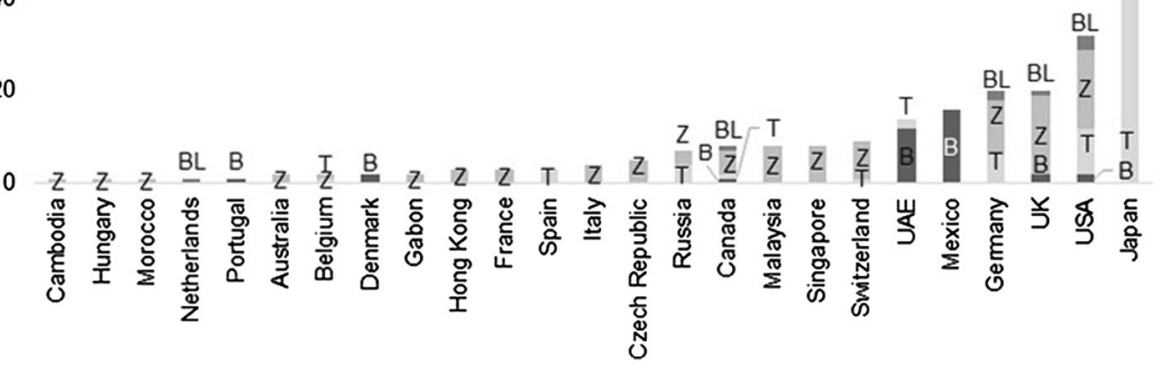

Fig. 4 Exporting and importing countries involved in the legal trade in live clouded leopards according to official CITES WCMC Records (1975 and 2013) 
we restricted our more detailed analyses to the number of live clouded leopards traded and CITES recorded seizures only.

\section{Live trade recorded by CITES}

In total, $70 \%(n=222)$ of the 316 CITES records referred to the legal trade in live clouded leopards (Appendix of ESM 1). According to the CITES comparative tabulation report, a total of 212 live clouded leopards was legally exported via 127 trade transactions during the period 1975 and 2013 (Table 1). Throughout this time, annual live exports varied between 1 and 6 animals with a mean average of 4 animals via an average of 2 trade transactions per year. In contrast, according to the same CITES data source, a total of 304 live clouded leopards was legally imported via 115 trade transactions during the same time period (Table 1). Throughout this time, annual live imports varied between 1 and 100 animals (the latter figure being an outlier; Fig. 3) with a mean average of 5 animals via an average of 2 trade transactions per year.

Linear trends analysis revealed that the quantity of live clouded leopard exported $\left(R^{2}=0.06\right)$ and imported $\left(R^{2}=0.04\right)$ both appear to have remained relatively constant during the period 1975 and 2013 (Fig. 3). However, in recent years (2008 and 2013) a relatively high volume of legal live trade has been recorded (Fig. 3). During this 6 years period alone, a total of 35 live animals was exported and 141 was imported. Notably, live imports peaked in 2009, largely due to a consignment (representing $33 \%$ of all live imports) of 100 captive bred live individuals of unknown geographic origin that was imported into Japan from the Republic of Korea (Appendix of ESM 1).

With regards to live imports, since 1975 when CITES record keeping first began, the live trade in clouded leopards appears to have shifted away from animals of unspecified origin for zoological purposes and towards that of captive animals primarily intended for commercial use (Fig. 3). During the initial period (1975 and 1981) no commercial breeding for commercial use was reported by CITES (Fig. 3). In contrast, during the most recent period (1998 and 2013) $56 \%(n=100)$ of imported live clouded leopards were reported to have been commercially bred in captivity for commercial use (Fig. 3).

Between 1975 and 2013, the legal export of live clouded leopards was reported from a total of 20 countries (Fig. 4). Surprisingly, the majority of exporters (75 \%,n=15) fall outside of the known geographical range of these species. Over the past 38 years the USA has been the most active exporter recorded by CITES with the majority of its 61 live clouded leopards (61\%; $n=37$ [individual clouded leopards]) traded for commercial purposes (Fig. 4). During the same time period, China $(n=37)$ and Thailand $(n=17)$ have been the two most active range country exporters in this regard. The CITES database also indicates that Cambodia $(n=2)$, Malaysia $(n=2)$ and Vietnam $(n=4)$ have been the only other range countries to have legally exported live clouded leopards since record keeping began (Fig. 4).

Between 1975 and 2013, the legal import of live clouded leopards was reported from a total of 25 countries (Fig. 4). The majority of importing countries ( $92 \%, n=23$ ) also fall outside of the known geographical range of this species. Over the past 38 years Japan has been the most active importer recorded by CITES with majority of its 131 live clouded leopards ( $85 \% ; n=111$ [individual clouded leopards]) traded for commercial purposes (Fig. 4). During the same time period, the USA was the second most active importer on record in this regard, with $31 \%(n=10)$ of its 32 live clouded leopards traded for commercial purposes (Fig. 4). The CITES database also indicates that Cambodia $(n=1)$ 
and Malaysia $(n=8)$ have been the only range countries to have legally imported live clouded leopards since record keeping began (Fig. 4).

\section{Seizures recorded by CITES}

In total, $8 \%(n=24)$ of the 316 CITES records referred to the seizure of illegally traded live clouded leopards and their derivatives (Appendix of ESM 1). According to the CITES comparative tabulation report, only one illegal seizure of a live clouded leopard was made during the period 1975 and 2013 (Table 1). The records indicate that this individual of unknown origin was exported from Hong Kong for zoological purposes and was confiscated in 1991 upon arrival in Germany (Appendix of ESM 1). During the same period 23 seizures involving clouded leopard derivatives took place (Table 1). In total, $52 \%$ of CITES derivative seizure records involved skins $(n=12), 22 \%$ involved bodies, $22 \%$ involved bone items, and $4 \%$ involved unspecified items (Fig. 5; Table 1).

We found that further analysis regarding the quantity of CITES items seized on import was not possible as unit data (required to describe and compare clouded leopard derivative seizures) was completely lacking (Table 1$)$. In total $17 \%(n=4)$ of the 23 derivative seizure records involved clouded leopard items that were exported from unknown sources (Appendix of ESM 1). One (4\%) seizure of a 'plate' was made on arrival in the USA following unlawful export from the UK (Table 1). The remaining 18 derivative seizure records involved body parts that were all exported from seven countries within Asia including Vietnam (26\%; $n=6$ ), Thailand (22\%), China (13\%), Indonesia (4\%), Lao PDR (4\%), Philippines (4\%) and Taiwan (4\%) (Appendix of ESM 1).

All of the 23 derivative seizures recorded took place upon import into three non-Asian countries, namely the Netherlands ( $4 \% ; n=1)$, New Zealand ( $4 \%$ ) and the USA (92\%) (Appendix of ESM 1). With regards to CITES purpose codes $22 \%$ of all seizures was reported to be for personal use and $4 \%$ was reported to be for zoological use (Appendix of

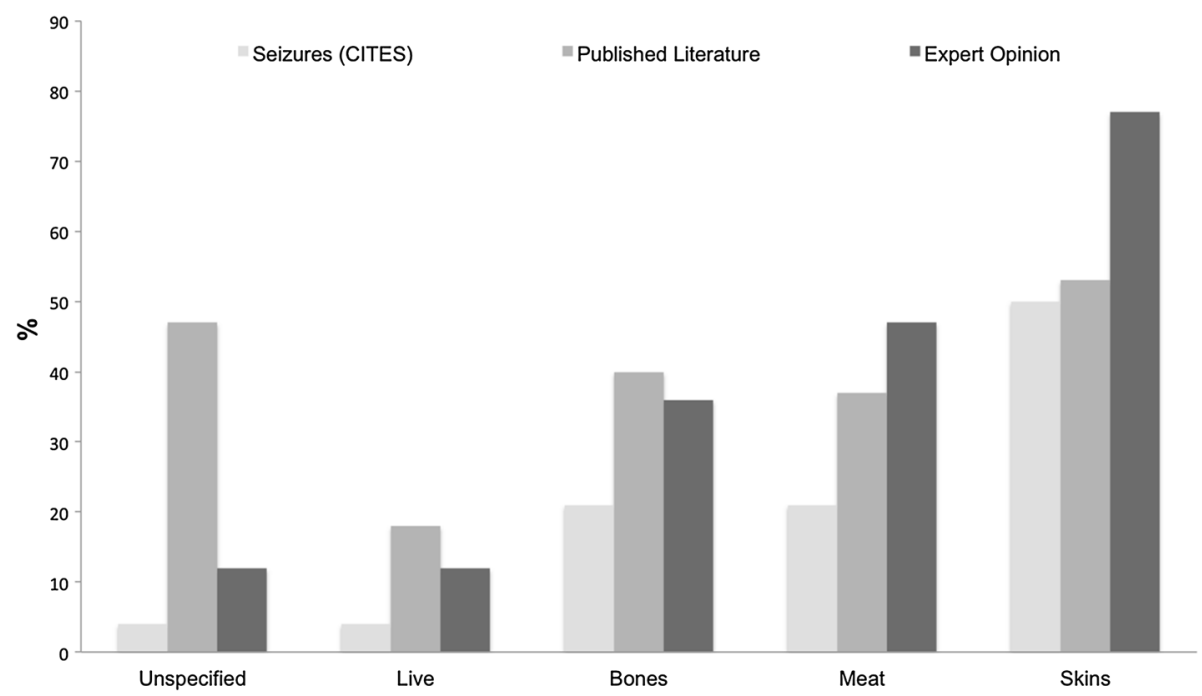

Fig. 5 Types of illegal clouded leopard trade reported by CITES WCMC Trade Database, in the published literature and by individuals in response to our survey of expert opinion (reported in percentage of seizure records, publications and survey responses respectively) 
ESM 1). However, no purpose code information was provided for the majority of derivative seizures (74\%) (Appendix of ESM 1).

\section{Literature review}

There were 127 sources (103 scientific papers and 24 grey reports) included in the literature review (Fig. 2). The mean rate of publication on clouded leopards between 1975 and 2013 was five papers and 0.6 reports per annum. The earliest paper and report included was published in 1986 and 2000 respectively (Fig. 6). Linear trends analysis revealed that the numbers of papers $\left(R^{2}=0.53\right)$ and reports $\left(R^{2}=0.39\right)$ mentioning these cats in the context of trade have increased over the past four decades (Fig. 6). Scientific attention peaked in $2011(n=18)$ and NGO attention peaked in $2012(n=5)$ (Fig. 6).

Only $14(11 \%)$ of these 127 sources (four papers and ten reports) focused primarily on issues related to the trade in clouded leopards (Fig. 2). With regards to the scale of the trade, three $(21 \%)$ of these 14 trade focused sources referred solely to the domestic trade within India. One (7\%) referred solely to cross border international trade between particular source and sink countries. Nine $(64 \%)$ referred to both domestic and international trade and one $(7 \%$ ) failed to distinguish between the two (Appendix of ESM 2).

Although it was not the main focus, the trade in clouded leopards was mentioned in an additional $28(22 \%)$ of these 127 sources (25 papers and three reports) (Fig. 2). For example trade in clouded leopards was briefly alluded to in the introduction and/or discussion of many of the papers included in this study or mentioned in passing as part of wider discussions regarding threats to general biodiversity in grey reports. However, a total of $22(52 \%)$ of all trade related sources $(n=42)$ failed to provide any specific information regarding clouded leopard trade chains (Appendix of ESM 2).

\section{Summary of published information}

A total of 18 (43\%; 7 papers and 11 reports) of all trade related sources cited countries of illegal domestic trade concern including: Cambodia $(5 \% ; n=2)$, China $(5 \%)$, India

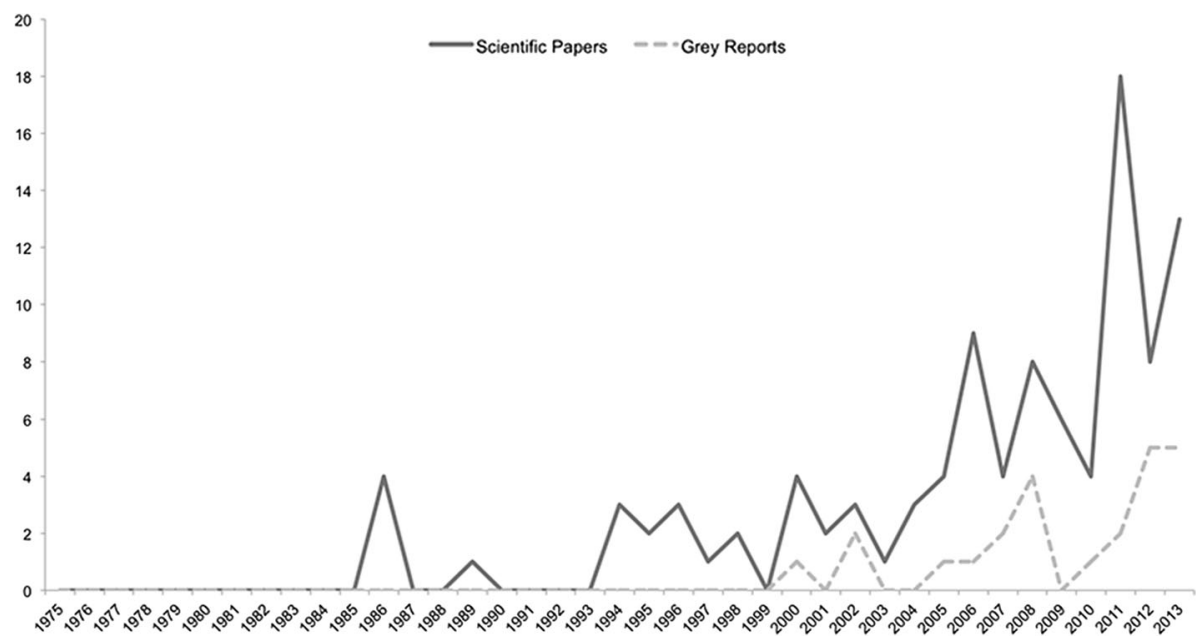

Fig. 6 Publication of clouded leopard focused publications between 1975 and 2013 (solid line represents scientific papers and dashed line represents grey reports) 
(14 \%), Indonesia (7 \%), Lao PDR (2\%), Malaysia (2\%), Myanmar (7 \%), Nepal (2\%), Thailand (7\%) and Vietnam (2\%) (Fig. 7). With regards to international trade, a total 14 (33\%; 5 papers and 9 reports) sources cited 'sink' countries (the final intended destinations) of illegal trade concern including: China $(17 \% ; n=7)$, Hong Kong (2\%), Indonesia (2\%), Korea (2\%), Myanmar (5\%), Russia (2\%), Taiwan (2\%), Thailand (10\%), USA ( $2 \%$ ), and Vietnam (5\%) (Fig. 7). Historic records of live specimens for use as pets into the UK and the Netherlands during the early $1900 \mathrm{~s}$ were also cited in two of the papers.

Unlike any of the scientific papers included in this study, three grey reports ( $7 \%$ of all trade related sources) provided specific information regarding certain towns with trade markets that are known to have engaged in the illegal trade of clouded leopards and their derivatives. Specific sites of particular concern include Kawthaung in south Myanmar; Keng Larb, Mong Hsat, Mong La, Mong Mit, Panghsang, and Tachilek in the Shan and Wa states of northern Myanmar; Boten, Thakek and Vieng Thong in Lao PDR; and Muang Sing and Nam Teuk in China (Fig. 7).

A total of 19 (45\%; 16 papers and 3 reports) of the 42 trade related sources failed to provide any specific information on the type of clouded leopard trade referred to within (Fig. 5). However, a total of 21 sources $(50 \%)$ specifically mentioned the trade in clouded leopard skins for ornamental purposes (Fig. 5) citing Cambodia (2\%), China (2\%), India (14\%), Indonesia (7\%), Laos PDR (7\%), Malaysia (2\%), Myanmar (12\%), Nepal (2\%), Thailand (5\%) and Vietnam (2\%) as source countries of concern (Fig. 7).

A total of $15(36 \%)$ sources referred to the trade in meat for subsistence (Fig. 5) citing China (2\%), India (10\%), Indonesia (10\%), Laos PDR (5\%), Malaysia (2\%), Myanmar

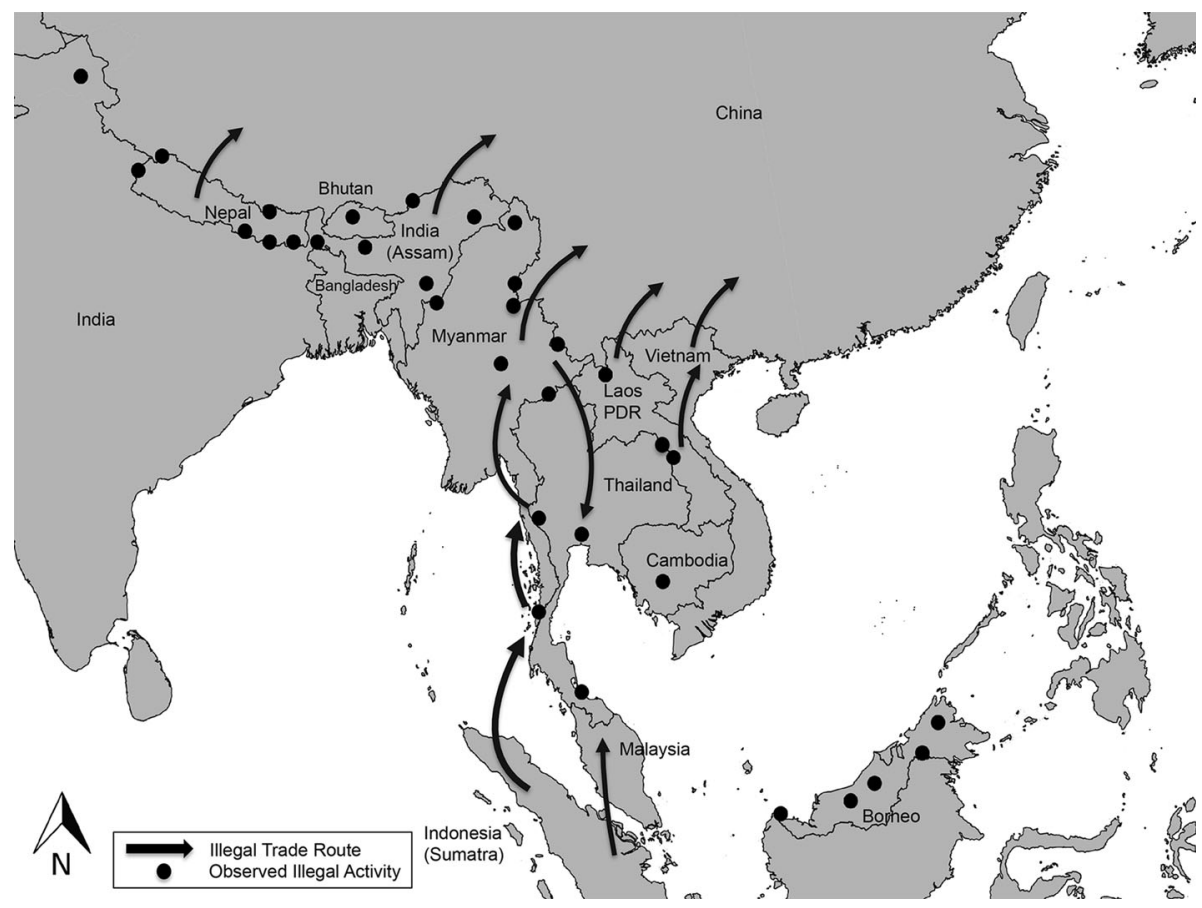

Fig. 7 Map of illegal trade routes in Asia and sites of observed illegal clouded leopard trade activity (live animals and derivatives) sourced via available literature and a survey of expert opinion 
(12\%), Nepal (2\%), Thailand (5\%) and Vietnam (2\%) as source countries (Fig. 7). A total of $15(36 \%)$ sources referred to trade in bones for medicinal purposes (Fig. 5) citing China (2\%), India (10\%), Indonesia (5\%), Laos PDR (5\%), Malaysia (2\%), Myanmar $(12 \%)$, Nepal (2\%), Thailand (5\%) and Vietnam (2\%) as source countries of concern (Fig. 7).

A total of nine $(21 \%)$ sources referred to trade in live animals as exotic pets for recreational purposes (Fig. 5) citing India (5\%), Indonesia (10\%), Laos PDR (5\%), Malaysia (2\%), Myanmar (12\%), Nepal (2\%), Thailand (2\%) and Vietnam (2\%) as source countries of concern (Fig. 7). Only 16 (38\%) of these clouded leopard tradefocused sources provided any information regarding the volume of trade.

One report (2\%) provided specific information relating to clouded leopard enforcement seizures made between 1997 and 2013 (TRAFFIC 2013). In total, it detailed seven different seizures made within China (29\%;n=2), Indonesia $(14 \%)$, Thailand (29\%), USA (14\%), and Vietnam (14\%). In total, these seizures involved at least three bodies, one full skeleton, three full skins and 100 skin pieces (TRAFFIC 2013). India (West Bengal) was specifically cited as a source country for one seizure (14\%) (TRAFFIC 2013). No source country data was provided for the other remaining seizures (86\%) (TRAFFIC 2013).

The majority ( $91 \% ; n=38$ ) of the sources that mentioned trade in any way referred to the negative conservation impacts caused by the illegal sourcing of wild caught clouded leopards. However, none of the scientific papers referred to the potential negative conservation impacts posed through legal captive breeding facilities (e.g. laundering of wild caught individuals). None of the sources included in this literature review referred to the negative animal welfare impacts associated with the trade in either wild caught or captive bred clouded leopards. However, technical and welfare challenges experienced by conservation (i.e. non commercial) captive breeding programs were extensively documented.

These breeding programs have been characterized by high incidence of male aggression (Kitchener 1999) to the extent that there have been at least 25 known fatal attacks on females in captivity recorded over the past 20 years (DeCaluwe et al. 2013). To negate infanticide cubs are often hand reared in captivity (DeCaluwe et al. 2013). Clouded leopards are also very sensitive to changes in their environment with exposure to novel objects, loud noises and new people documented as stressors (DeCaluwe et al. 2013). These generally anxious animals display a diversity of stress behavior in captivity including hair plucking, tail chewing, pacing and excessive hiding (Wielebnowski et al. 2002).

\section{Expert opinion}

We approached 40 clouded leopard experts and received formal responses from a total of 24 individuals $(60 \%)$. We received 17 completed questionnaires from individuals with a working knowledge from eight of the known clouded leopard range countries including Bhutan (6\%;n=1); Cambodia (6 \%); India (6\%); Indonesia (18\%); Lao PDR (6\%); Malaysia (18\%); Myanmar (18\%) and Thailand (24\%). We were unable to obtain any formal responses from individuals working in China, Bangladesh or Nepal. The remaining eight respondents did not fill in a questionnaire but provided additional informed insight.

A total of 13 of the 17 questionnaire respondents (77\%) provided information regarding specific illegal trade activity. The majority $(65 \% ; n=11)$ stated direct observation as a source of their information. However, verbal reports from trusted contacts $(35 \%)$, media reports $(12 \%)$, scientific papers $(12 \%)$, published reports $(6 \%)$ and 
unpublished reports $(6 \%)$ were also cited. A total of seven respondents $(41 \%)$ described illegal activity that had taken place within 6 months prior to questionnaire distribution. The remaining respondents $(35 \% ; n=6)$ all referred to activity that had taken place within the last 10 years.

A total of 15 questionnaire respondents $(88 \%)$ cited countries of domestic illegal trade concern including: Bhutan (6\%;n=1), Cambodia (6\%), India (6\%), Indonesia (18\%), Lao PDR (6 \%), Malaysia (12\%), Myanmar (18\%) and Thailand (18\%) (Fig. 7). With regards to sink countries, a total of 14 respondents $(82 \%)$ cited sink countries of international illegal trade concern including: China $(47 \% ; n=8)$, India $(6 \%)$, Myanmar (6\%), Tibet (6\%), Thailand (7\%) and Vietnam (12\%) (Fig. 7). Experts reported China as sourcing illegal derivatives from at least five different clouded leopard range countries (Cambodia, India, Lao PDR, Myanmar and Thailand) (Fig. 7).

Some of the 17 questionnaire respondents were able to provide specific information regarding certain towns where illegal trade activity is known to have occurred. Specific sites of particular concern include Phobjikha in Bhutan; Phnom Penh in Cambodia; Digboi, Kokrajhar and Seijosa in India; Jakarta in Indonesia; Bakun dam, Kapit, Nabawan, Pensiangan and Sematan in Malaysia; Bangkok, Ban Pa Deng, Ranong and Songkhla in Thailand; and Khaw Thaung, Laiza, Putao, Naung Shwe, and Tachilek in Myanmar (Fig. 7).

Discussions with remaining experts identified two additional key reports that were not encountered during our main literature review. Information provided therein brings attention to a number of additional towns with illegal trade markets known to engage in big
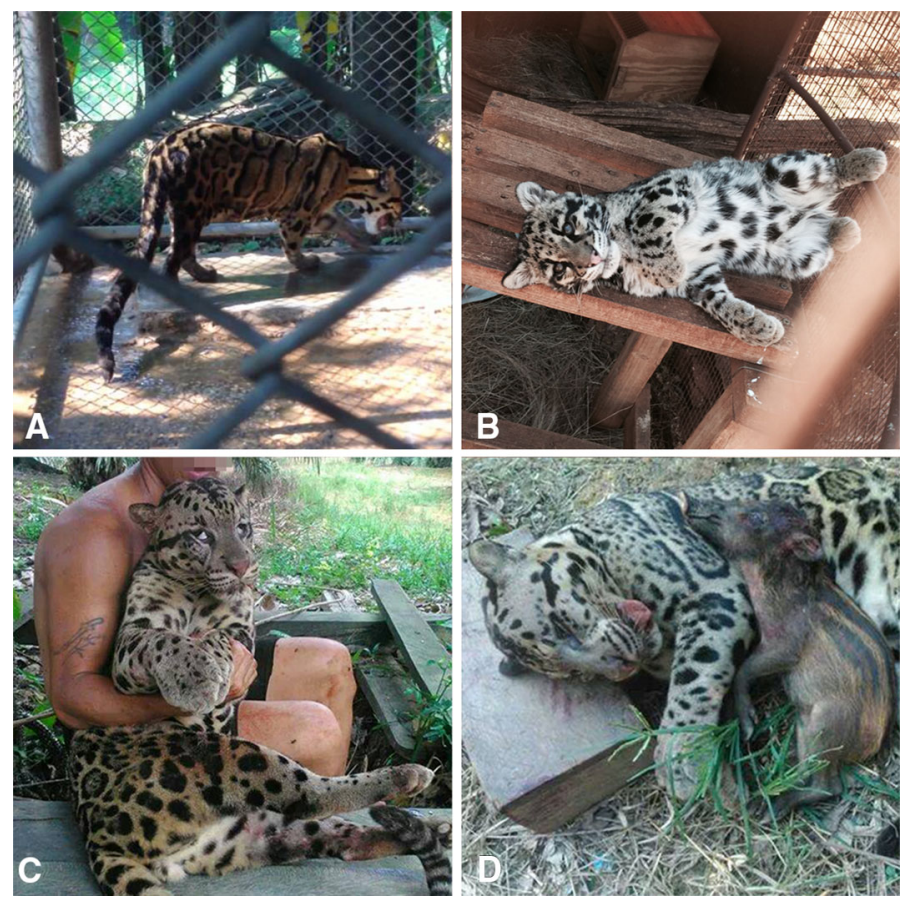

Fig. 8 a 'Screen shot' of a captive clouded leopard taken from footage of the 'Muang Thong Tiger farm' in Laos PDR during early 2014. b A captive clouded leopard cub taken at the Rhino and Lion Nature Reserve in South Africa. c and d Clouded leopard carcasses shared online via 'Bakunparadise' social media group 
cat trade along the borders of China, India and Nepal (Nowell and Pervushina 2014). Specific sites of particular concern include: Burang (China); Dharchula, Imphal, Leh, Moreh, Raxaul, and Siliguri (India); and Biratnagar, Birgunj, and Zhangmu (Nepal) (Fig. 7).

With regards to the frequency of illegal trade type and intended use cited, expert opinion broadly reflected CITES seizure records and our literature review. A total of 13 (77\%) questionnaire respondents specifically mentioned clouded leopard skins for decorative purposes, eight $(47 \%)$ reported trade in meat for subsistence consumption, six $(35 \%)$ reported trade in bones for use as traditional medicine and two (12\%) reported trade in live animals for use as exotic pets (Fig. 5). Only two questionnaire respondents (12\%) failed to provide any specific information on the type and intended use of clouded leopard trade within their selected country (Fig. 5). Two experts (12\%) cited concerns that clouded leopard derivatives were being sourced as an alternative to tiger derivatives.

None of the 17 questionnaire respondents referred to illegal activity related to the captive breeding of clouded leopards. However, discussions with one expert confirmed that this is of potential concern (Anonymous pers. comms. 2014). Undercover footage taken in early 2014 confirmed the presence of clouded leopards at the Muang Thong Tiger Farm in Lao PDR (Hargreaves 2014; Anonymous pers. comms. 2014) and a further 27 at Ubon zoo (a known supplier of wildlife for commercial use) in Thailand (Environment for Nature Vietnam (ENV) 2014) (Fig. 8). Film footage taken in mid 2014 also confirmed the presence of a juvenile clouded leopard at the Rhino and Lion Nature Reserve in South Africa (also a supplier of wildlife for commercial use) (World Animal Protection 2015). Discussions with three experts also confirmed that illegal activity regarding to clouded leopards could also be easily observed online. For example, four photos featuring four clouded leopard carcasses were posted by members of a single Malaysian online social media group entitled 'Bakunparadise' between April 24th and November 08th 2014 (Facebook 2014) (Fig. 8).

According to the 17 questionnaire respondents, illegal direct take from the wild is currently having a medium to high negative impact [mean average score of $5(n=15)$ ] on the conservation of clouded leopards. In their opinion, this type of activity is also having a medium negative impact on their welfare [mean average score of $4(n=16)$ ]. These same respondents indicated that illegal trade in these species is increasing [mean average score of $5(n=15)$ ] with respondents specifically citing India $(n=1 ; 6 \%)$, Indonesia $(6 \%)$, Laos PDR (6\%), Malaysia (6\%), Myanmar (6\%) and Thailand (24\%) as source countries of increasing concern. All respondents also stated that current efforts to address it are inadequate [mean average score of $2(n=15)]$.

\section{Discussion}

\section{Commercial captive breeding}

According to CITES records, the live trade in clouded leopards has remained relatively constant over the last four decades. However, during this time improved reporting has helped to reveal a dramatic switch away from animals of unspecified origin (presumably some of which were wild) for zoological purposes and towards that of captive bred animals primarily intended for commercial use. Shifts towards more highly managed and concentrated systems such as captive breeding are often associated with increased trade 
controls (Robinson et al. 2015). Although wild clouded leopards have received full protection since 1975, increased scrutiny by CITES Management Authorities (UNEP-WCMC 2013) and trade exemptions for captive bred specimens may have encouraged wildlife traders to make this transition in order to meet continued consumer demand for exotic pets and wildlife tourism.

China and Thailand have been the most active range country exporters with regards to the quantity of live clouded leopards traded for commercial purposes. Both countries are also characterized by large captive populations of other big cats (e.g. $>5000$ and $>900$ captive tigers respectively) (Environment for Nature Vietnam (ENV) 2014) and have also been criticized for the commercial components of these captive breeding programs (e.g. Environmental Investigations Agency (EIA) 2013). Broadly, there are concerns that these operations are stimulating demand for cheaper more preferable wild caught specimens (Kirkpatrick and Emerton 2010; Gratwicke et al. 2008), creating a legal loophole for the illegal laundering of wild animals and their derivatives (Gratwicke et al. 2007; Dutton et al. 2013). Others have highlighted that they typically involve animals that cannot be successfully released as part of wild reintroduction programs due to concerns relating to survivability, human-wildlife conflicts, the introduction of disease and genetic pollution (Schmidt-Burbach et al. 2015). Concerns regarding the role of clouded leopards as potential invasive species in non range countries have also been raised (Anonymous, pers. comms. 2014).

Disturbingly, it seems certain that clouded leopards are now also being incorporated into these and other similar commercial operations elsewhere. Our correspondents reported the presence of clouded leopards at several range country facilities known to have engaged in illegal trade activity. For example the Muang Thong Tiger Farm (described as the 'largest tiger farm in Southeast Asia') in Lao PDR and Ubon Zoo in Thailand have both been repeatedly criticized for the illegal sale of live tigers and their body parts (Environment for Nature Vietnam (ENV) 2014). This type of illicit activity fuels concerns that illegally sourced wild caught specimens will be also be used as (possibly cheaper) preferable alternatives to bolster breeding stocks. Many of these facilities (such as the Rhino and Lion Nature Reserve in South Africa) also act as tourist attractions where a high level of human contact with big cats such as lions and tigers is permitted (Williams et al. 2015). Given the difficulties associated with successfully breeding clouded leopards and the challenges of meeting their basic welfare needs in captivity (Wielebnowski et al. 2002), there are also concerns that they will be unable to adapt well to intensive commercial conditions such as this.

Japan was the largest importer of live clouded leopards for commercial purposes. In 2009, the largest legal consignment on record (involving 100 live specimens) was received from the Republic of Korea, a non range country (UNEP-WCMC 2014). Incomplete records (especially with regards to country of origin), contradictory import and export figures and the high number of animals involved call the validity of this particular trade transaction into question. Whether this record represents a clerical error or a successful attempt to launder specimens using fraudulent paper work, it serves to highlight another legal loophole. Specifically, CITES Management Authorities do not currently monitor, or report on, the final or subsequent destination of legally traded Appendix of ESM 1 specimens (Harrington pers. comms. 2015). As such it is not possible to confirm the location (or even existence) of these 'missing' 100 clouded leopards.

The USA was the most active exporter, and second most active importer, of clouded leopards intended for commercial purposes. This is perhaps unsurprising given the widespread private ownership (approx. 10,000 and 20,000 big cats International Fund for 
Animal Welfare (IFAW) 2012), and ready availability of public interactions with big cats at zoos, fairgrounds, and other public areas (International Fund for Animal Welfare (IFAW) 2012). Currently, a patchwork of state and federal regulations govern the private ownership and public interactions with big cats (International Fund for Animal Welfare (IFAW) 2012). However, despite increasing recognition of the threats to public safety, animal and conservation, legislation in many states does not currently extend to clouded leopards as they are often considered not to be big cats (e.g. New York State's 2015 law prohibiting public contact New York State Assembly 2014).

\section{Illegal poaching for derivatives}

Acknowledging a varying degree of experience and proficiency among experts, illegal poaching for derivatives remains cited as a medium to high threat to clouded leopards by those currently focused on these species. Bones for use as traditional medicine and meat for subsistence purposes was mentioned across all data sources utilized in this study. However, illegal trade in skin for decorative purposes was cited most frequently. Whether this prominence is genuine or simply a reporting bias due to the likelihood that skins are easier to observe, as they are typically displayed for decoration, (Nowell and Jackson 1996) remains to be determined. It is also possible that an unknown amount of undocumented irregular 'cryptic' trade is taking place due to the enforcement challenges associated with correctly identifying clouded leopard derivatives (Anonymous pers. comms. 2015). Irrespective of its true scale, illegal activity involving clouded leopard derivatives is prevalent in all range states and can be openly observed at markets where enforcement is either weak or lacking (e.g. Nijman and Shepherd 2015). Markets located in remote and lawless areas including porous international borders (e.g. China, Myanmar, India and Nepal) were cited to be of particular concern (Nowell and Pervushina 2014; Nijman and Shepherd 2015).

Illegal activity involving clouded leopards can also be openly observed online (International Fund for Animal Welfare) (International Fund for Animal Welfare (IFAW) 2014). Experts contributing to our study reported the use of social media to document and distribute photographic evidence of clouded leopard poaching (Wong pers. comms. 2014). In particular, we were directed to a Malaysian online media group that also shared evidence of other poaching activity including other species such as Asian palm civets (Paradoxurus hermaphrodites) sambar deer (Rusa unicolor) and boar (Sus scrofa). The application of social media as a tool to facilitate enforcement action is being increasingly recognized as an innovative, accessible and cost effective approach to protect wild species (e.g. Mongabay 2014; NBC News 2014) and could be encouraged throughout all clouded leopard range states.

Despite widespread illegal trade concern, we found specific information (both quantitative and qualitative) regarding the direct impacts on clouded leopard welfare and conservation to be virtually nonexistent. This paucity of data could be due to a combination of different factors. Firstly, its illegal nature means that an unknown amount of activity is deliberately conducted covertly e.g. smuggling (Barber-Meyer 2010). Secondly, its criminal element and associated personal safety risks could be a significant research deterrent (Wyler and Sheikh 2009). Thirdly, researchers may choose, or be legally bound, to withhold such data in order to facilitate arrests and subsequent prosecutions (Anon, pers. comms. 2014). Alternatively, to date, this type of research may not have fallen under the direct remit of researcher, donor agency and peer-reviewed journal editorial strategies that are often subject to fads and fashions (D'Cruze et al. 2009). The root causes aside, it is also 
not currently possible to determine the scale, trade dynamics or impacts of illegal poaching from the current publically available records.

\section{Conclusion}

We argue that this paucity of data is not grounds for complacency, but rather suggests a need for researchers to focus their efforts on gathering socioeconomic data that will provide detailed insights into the type, volume, trade routes and attitudes of poachers, traders and consumers involved in this illegal trade activity (e.g. TRAFFIC 2008). In particular, the consumer demand aspects of the live trade of clouded leopards are poorly understood

Table 2 Key challenges and management recommendations for regulating clouded leopard (and other big cat) trade

\begin{tabular}{|c|c|c|}
\hline Concern & Continuing challenges & Recommendations \\
\hline \multirow{3}{*}{$\begin{array}{l}\text { Legislative and } \\
\text { regulatory } \\
\text { measures }\end{array}$} & $\begin{array}{l}\text { Legal international commercial } \\
\text { trade in captive bred individuals }\end{array}$ & $\begin{array}{l}\text { Extend existing trade bans to include } \\
\text { commercial trade in captive bred individuals }\end{array}$ \\
\hline & $\begin{array}{l}\text { Legal national wild hunting } \\
\text { quotas (in Laos PDR) }\end{array}$ & $\begin{array}{l}\text { Extend existing national trade legislation to } \\
\text { prohibit all hunting in Laos PDR }\end{array}$ \\
\hline & $\begin{array}{l}\text { Legal national maintenance of } \\
\text { existing derivative stockpiles }\end{array}$ & $\begin{array}{l}\text { Extend existing national legislation to include } \\
\text { the maintenance of derivative stockpiles }\end{array}$ \\
\hline \multirow{4}{*}{$\begin{array}{l}\text { National and } \\
\text { international law } \\
\text { enforcement }\end{array}$} & $\begin{array}{l}\text { Illegal trade along international } \\
\text { borders }\end{array}$ & $\begin{array}{l}\text { Increase cooperation between national } \\
\text { enforcement bodies }\end{array}$ \\
\hline & $\begin{array}{l}\text { Illegal trade 'laundered' via } \\
\text { commercial captive breeding } \\
\text { facilities }\end{array}$ & $\begin{array}{l}\text { Introduce 'DNA' database and adopt zero } \\
\text { tolerance to illegal trade 'laundered' via } \\
\text { commercial captive breeding facilities }\end{array}$ \\
\hline & Illegal trade advertised online & $\begin{array}{l}\text { Adopt zero tolerance to illegal trade advertised } \\
\text { online }\end{array}$ \\
\hline & $\begin{array}{l}\text { Illegal growth of national } \\
\text { derivative stockpiles }\end{array}$ & $\begin{array}{l}\text { Periodically destroy all national privately held } \\
\text { derivative stockpiles }\end{array}$ \\
\hline \multirow{4}{*}{$\begin{array}{l}\text { Trade data } \\
\text { recording and } \\
\text { analysis }\end{array}$} & Incomplete national trade records & $\begin{array}{l}\text { Create systematic national data management } \\
\text { platforms }\end{array}$ \\
\hline & $\begin{array}{l}\text { Incomplete and contradictory } \\
\text { CITES WCMC international } \\
\text { trade records }\end{array}$ & $\begin{array}{l}\text { Strengthen existing CITES WCMC international } \\
\text { data management platforms }\end{array}$ \\
\hline & $\begin{array}{l}\text { Incomplete national privately } \\
\text { owned derivative stockpile } \\
\text { records }\end{array}$ & $\begin{array}{l}\text { Declare size and location of all national } \\
\text { privately held derivative stockpiles }\end{array}$ \\
\hline & $\begin{array}{l}\text { Incomplete national commercial } \\
\text { captive bred clouded leopard } \\
\text { records }\end{array}$ & $\begin{array}{l}\text { Declare number and location of all live animals } \\
\text { currently held at commercial captive breeding } \\
\text { facilities }\end{array}$ \\
\hline \multirow[t]{2}{*}{$\begin{array}{l}\text { Consumer demand } \\
\text { reduction }\end{array}$} & $\begin{array}{l}\text { Emerging international demand } \\
\text { for commercial captive bred } \\
\text { live animals }\end{array}$ & $\begin{array}{l}\text { Initiate new international behavior change } \\
\text { focused interventions }\end{array}$ \\
\hline & $\begin{array}{l}\text { Sustained domestic demand for } \\
\text { wild caught live animals and } \\
\text { derivatives }\end{array}$ & $\begin{array}{l}\text { Strengthen existing national behavior change } \\
\text { focused interventions }\end{array}$ \\
\hline
\end{tabular}


with research required to establish whether clouded leopards, and indeed other big cat species, are being targeted as a substitute for tiger derivatives. At specific locations clouded leopards have been documented to be the most illegally species of Asian big cat (e.g. Nijman and Shepherd 2015). As such, especially given that wild populations are thought to comprise less than 10,000 individuals, this data is required to help inform future discussions regarding the IUCN Red List status of both clouded leopard species. The total number of clouded leopards involved in commercial captive breeding programs should also be established and the impacts of this emerging industry on wild populations should be further investigated. Attention should also focus on the physical and mental conditions of the animals in these intensive commercial operations.

The commercial production of big cats, such as tigers, is already of widespread conservation and animal welfare concern (e.g. Environmental Investigations Agency (EIA) 2013). This is exemplified by Decision 14.69 of CITES Resolution Conf. 12.5 (Rev. CoP16) which calls for Parties to restrict captive populations to a level supportive only to conserving wild tigers, with no associated trade in their derivatives. Clouded leopards are now also being threatened by this particular aspect of trade. As such, we support immediate calls for the registration of all big cat 'farms', captive individuals and the monitored destruction of all derivatives from deceased individuals (captive mortalities) (Table 2). As an ultimate precautionary measure we support calls to extend existing international and national big cat trade bans so that they also include commercial trade in captive bred individuals (Nowell and Pervushina 2014).

Expert opinion indicates that illegal trade activity is on the increase and that not enough is currently being done to protect the less than 100,000 clouded leopards remaining in the wild. Illegal wildlife trade is major threat to the survival of all Asian big cats with illegal actors typically trafficking multiple species along the same domestic and international routes (e.g. Nowell and Pervushina 2014). As such, to address the conservation and welfare threats posed by the illegal trade in clouded leopard (and other big cat species), we support existing calls for increased cooperation between national enforcement bodies, improved compliance of the CITES WCMC and other national data management platforms, the registration and periodic destruction of any privately held stockpiles and the development of comprehensive legal frameworks to prevent laundering via legal commercial breeding facilities (Table 2).

Acknowledgments We thank Megan Baker, Emma Bush, Margaret Balaskas, Christine Breitenmoser, Ozgun Emre Can, Gemma Carder, Will Duckworth, Gabriella Fredriksson, Melvin Gumal, Iding Achmad Haidir, Lauren Harrington, Kate Jenks, Rini Kumala, Godwin Limburg, Matthew Linkie, Anthony Lynam, Nick Marx, Sapai Min, Annirudha Mookerjee, Tom Morrison, Luke Nicholson, Helen Procter, Akchousanh Rasphone, Jan Schmidt-Burbach, Anthony Sebastian Robert Steinmetz, Vivienne Williams and Siew Te Wong for their invaluable comments and insights during this research project. Many thanks to the Investigation and Intelligence Team at World Animal Protection, and anonymous contributors, who provided confidential information in support of this research. Special thanks to Steve McIvor for his support on this project. Funding was provided by World Animal Protection.

\section{Compliance with ethical standards}

Conflict of Interest The authors declare that they have no conflict of interest.

Open Access This article is distributed under the terms of the Creative Commons Attribution 4.0 International License (http://creativecommons.org/licenses/by/4.0/), which permits unrestricted use, distribution, and reproduction in any medium, provided you give appropriate credit to the original author(s) and the source, provide a link to the Creative Commons license, and indicate if changes were made. 


\section{References}

Austin SC, Tewes ME (1999) Ecology of the clouded leopard in Khao Yai National Park, Thailand. Cat News IUCN SSC 31

Baker S, Cain R, Kesteren F, Zommers Z, D'Cruze N, Macdonald D (2013) Rough trade: animal welfare in the global wildlife trade. Bioscience 63:928-938

Barber-Meyer SM (2010) Dealing with the clandestine nature of wildlife-trade market surveys. Conserv Biol 24:918-923

Bauer H, Packer C, Funston PF, Henschel P, Nowell K (2015). Panthera leo. The IUCN Red List of Threatened Species. Version 2015.2. www.iucnredlist.org. Accessed 13 Aug 2015

Buckley-Beason VA, Johnson WE, Nash WG, Stanyon R, Menninger JC, Driscoll CA, Howard J, Bush M, Page JE, Roelke ME, Stone G, Martelli PP, Wen C, Ling L, Duraisingam RK, Lam PV, O’Brien SJ (2006) Molecular evidence for species-level distinctions in clouded leopards. Curr Biol 16:2371-2376

Bush ER, Baker SE, Macdonald DW (2014) Global trade in exotic pets 2006-2012. Conserv Biol 28:663-676

D'Cruze N, Henson D, Olsson A, Emmett D (2009) The importance of herpetological survey work in conserving Malagasy biodiversity: are we doing enough? Herpet Rev 40:19-25

DeCaluwe HB, Wielebnowski NC, Howard J, Pelican KM, Ottinger M (2013) Behavioral reactions relate to adrenal activity and temperament in male clouded leopards (Neofelis nebulosa). Appl Anim Behav Sci 149:63-71

Driscoll CA, Macdonald DW, O’Brien SJ (2009) From wild animals to domestic pets, an evolutionary view of domestication. P Natl Acad Sci 106:9971-9978

Dutton AJ, Gratwicke B, Hepburn C, Herrera EA, Wunder S (2013) Tackling unsustainable wildlife trade. In: Macdonald DW, Willis KJ (eds) Key topics in conservation biology. Wiley-Blackwell, New York, pp 74-92

Environment for Nature Vietnam (ENV) (2014) Caged assets: tiger farming and trade. http://eiainternational.org/wp-content/uploads/Caged-Assets-revised.pdf. Accessed 01 Jan 2015

Environmental Investigations Agency (EIA) (2013) Hidden in plain sight China's clandestine tiger trade. http://eia-international.org/reports/hidden-in-plain-sight-chinas-clandestine-tiger-trade. Accessed 01 Jan 2015

Facebook (2014) Bakun Paradise social online media group https://www.facebook.com/pages/ Bakunparadise/330974893624478?fref=ts Accessed 01 May 2014

Fitzherbert E, Caro T, Johnson PJ, Macdonald DW, Borgerhoff Mulder M (2014) From avengers to hunters: leveraging collective action for the conservation of endangered lions. Biol Conserv 174:84-92

Goodrich J, Lynam A, Miquelle D, Wibisono H, Kawanishi K, Pattanavibool A, Htun S, Tempa T, Karki J, Jhala Y, Karanth U (2015) Panthera tigris. The IUCN Red List of Threatened Species. Version 2015.2. www.iucnredlist.org. Accessed 13 Aug 2015

Grassman LI Jr, Tewes ME, Silvy NJ, Kreetiyutanont K (2005) Ecology of three sympatric felids in a mixed evergreen forest in North-central Thailand. J Mammal 86:29-38

Gratwicke B, Bennett E, Broad S, Christie S, Dutton A, Gabriel G, Kirkpatrick C, Nowel K (2007) The world can't have wild tigers and eat them, too. Conserv Biol 22:222-223

Gratwicke B, Mills J, Dutton A, Gabriel G, Long B, Seidensticker J, Wright B, You W, Zhang L (2008) Attitudes toward consumption and conservation of tigers in China. PLoS One 3:1

Hargreaves R (2014) Independent pro bono legal analysis for Item 38 on the agenda for the 65th Meeting of the CITES Standing Committee concerning Asian big cats. Unpublished report

Harrington LA (2015) International commercial trade in live carnivores and primates 2006-2012: response to Bush et al. 2014. Conserv Biol 29: 293-296

Hearn A, Sanderson J, Ross J, Wilting A, Sunarto S (2008) Neofelis diardi. The IUCN Red List of Threatened Species. Version 2014.3.www.iucnredlist.org. Accessed 01 Jan 2015

International Fund for Animal Welfare (IFAW) (2012) Stopping private ownership of big cats. http://www. ifaw.org/sites/default/files/Big\%20Cats\%20Fact\%20Sheet_0.pdf. Accessed 01 Jan 2015

International Fund for Animal Welfare (IFAW) (2014) Wanted dead or alive: Exposing online wildlife trade. http://www.ifaw.org/united-states/resource-centre/wanted-dead-or-alive-exposing-online-wildlife-trade. Accessed 01 Jan 2015

International Species Information System (ISIS) (2014) http://www2.isis.org/news/Pages/UsersConference. aspx. Accessed 01 Jan 2015

Kirkpatrick RC, Emerton L (2010) Killing tigers to save them: fallacies of the farming argument. Conserv Biol 24:655-659

Kitchener AC (1999) Mate killing in clouded leopards: ahypothesis. Int Zoo News 46(4):221-224 
Kitchener AC, Beaumont MA, Richardson D (2006) Geographical variation in the clouded leopard, Neofelis nebulosa, reveals two species. Curr Biol 16:2377-2383

Low J (1991) The smuggling of endangered wildlife across the Taiwan Strait. TRAFFIC International, Cambridge

Macdonald DW, Burnham D, Hinks AE, Wrangham R (2012) A problem shared is a problem reduced: seeking efficiency in the conservation of felids and primates. Folia Primatol 83:171-215

Mongabay (2014) Conservationists use social media to take on Peru's booming illegal wildlife trade http:// news.mongabay.com/2014/0905-dasgupta-peru-wildlife-trade.html Accessed 04 Sep 2014

New York State Assembly (2014) A09004 Text http://assembly.state.ny.us/leg/?default_fld=\&bn=A0900 $4 \&$ term $=2013 \&$ Summary $=$ Y\&Actions $=$ Y \&Votes $=$ Y\&Text $=$ Y. Accessed 01 Jan 2015

NBC News (2014) Social media post leads feds to bust Nevada wildlife poachers. http://www.nbcnews.com/ news/us-news/social-media-post-leads-feds-bust-nevada-wildlife-poachers-n246296. Accessed 01 Jany 2015

Nijman V, Shepherd CR (2015) Trade in tigers and other wild cats in Mong La and Tachilek, Myanmar-a tale of two border towns. Biol Conserv 182:1-7

Nowak RM (2005) Walker's Mammals of the World. Johns Hopkins University Press, Baltimore

Nowell K (1990) Formosa and the clouded leopard. Cat News 13:15

Nowell K, Jackson P (1996) Wild cats. Status survey and conservation action plan. IUCN SSC Cat Specialist Group, Gland and Cambridge

Nowell K, Pervushina N (2014) Review of implementation of resolution conf. 12.5 (REV. COP16) on conservation of and trade in tigers and other Appendix-I Asian big cat species. Unpublished report

Robinson JE, Griffiths RA, St. John FAV, Roberts DL (2015) Dynamics of the global trade in live reptiles: Shifting trends in production and consequences for sustainability. Biol Conserv 184: 42-50

Salter R (1983) Summary of currently available information on internationally threatened wildlife species in Burma. Unpublished report

Sanderson J, Khan JA, Grassman L, Mallon DP (2008) Neofelis nebulosa. The IUCN Red List of Threatened Species. Version 2014.1. www.iucnredlist.org. Accessed 01 Jan 2015

Schmidt-Burbach J, Ronfot D, Srisangiam R (2015) Asian elephant (Elephas maximus), pig-tailed macaque (Macaca nemestrina) and tiger (Panthera tigris) populations at tourism venues in Thailand and aspects of their welfare. Submitted to PLoS One 10(9): e0139092. doi:10.1371/journal.pone.0139092

TRAFFIC (2008) What's driving the wildlife trade? A review of expert opinion on economic and social drivers of the wildlife trade and trade control efforts in Cambodia, Indonesia, Lao PDR and Vietnam. East Asia and Pacific region sustainable development discussion papers. East Asia and Pacific Region Sustainable Development Department, World Bank, Washington DC

TRAFFIC (2013) Bulletin seizures and prosecutions March 1997-October. TRAFFIC International, Cambridge

UNEP-WCMC (2013) CITES trade-a global analysis of trade in Appendix I-listed species United Nations Environment Programme World Conservation Monitoring Centre, Cambridge

UNEP-WCMC (2014) A guide to using the CITES Trade Database, version 8. United Nations Environment Programme-World Conservation Monitoring Centre. http://trade.cites.org/cites_trade_guidelines/enCITES_Trade_Database_Guide.pdf. Accessed 01 May 2014

Wielebnowski NC, Fletchall N, Carlstead K, Busso JM, Brown JL (2002) Noninvasive assessment of adrenal activity associated with husbandry and behavioral factors in the North American clouded leopard population. Zoo Biol 21:77-98

Williams VL, Newton DJ, Loveridge AJ, Macdonald DW (2015). Bones of contention: an assessment of the South African trade in African Lion Panthera leo bones and other body parts. TRAFFIC, Cambridge, UK

World Animal Protection (2015) Unpublished report. World Animal Protection, London, UK

Wyler LS, Sheikh PA (2009) International illegal wildlife trade: Threats and US policy. Congressional Research Service, Washington, DC 